\title{
Thermal comfort control via air conditioning system using fuzzy neural network feedback controller
}

\author{
Somaye A. Mohamadi, Abdulraheem J. Ahmed \\ Department of Information Technology, Zakho Technical Institute, Duhok Polytechnic University, Iraq
}

\begin{tabular}{|c|c|}
\hline Article Info & ABSTRACT \\
\hline $\begin{array}{l}\text { Article history: } \\
\text { Received Dec 24, } 2019 \\
\text { Revised Feb 26, } 2020 \\
\text { Accepted Mar 13, } 2020\end{array}$ & $\begin{array}{l}\text { Despite their complexity and uncertainty, air conditioning systems should } \\
\text { provide the optimal thermal conditions in a building. These controller } \\
\text { systems should be adaptable to changes in environmental parameters. In most } \\
\text { air conditioning systems, today, there are On/Off controllers or PID in more } \\
\text { advanced types, which, due to different environmental conditions, are not } \\
\text { optimal and cannot provide the optimal environmental conditions. }\end{array}$ \\
\hline \multirow[t]{2}{*}{$\begin{array}{l}\text { Keywords: } \\
\text { Air conditioning } \\
\text { Fuzzy controller } \\
\text { Neural network } \\
\text { Thermal comfort }\end{array}$} & $\begin{array}{l}\text { Controlling thermal comfort of an air conditioning system requires } \\
\text { estimation of thermal comfort index. In this study, fuzzy controller was used } \\
\text { to provide thermal comfort in an air conditioning system, and neural network } \\
\text { was used to estimate thermal comfort in the feedback path of the controller. } \\
\text { Fuzzy controller has a good response given the non-linear features of air } \\
\text { conditioning systems. In addition, the neural network makes it possible to use } \\
\text { thermal comfort feedback in a real-time control. }\end{array}$ \\
\hline & $\begin{array}{r}\text { Copyright } @ 2020 \text { Institute of Advanced Engineering and Science. } \\
\text { All rights reserved. }\end{array}$ \\
\hline \multicolumn{2}{|l|}{ Corresponding Author: } \\
\hline \multicolumn{2}{|c|}{$\begin{array}{l}\text { Somaye A. Mohamadi, } \\
\text { Duhok Polytechnic University, } \\
61 \text { Zakho Road, Duhok, Iraq. } \\
\text { Email: abdulraheem.ahmed@dpu.edu.krd }\end{array}$} \\
\hline
\end{tabular}

\section{INTRODUCTION}

Today, modern heating, purification and air conditioning systems should provide comfort of the occupants in addition to optimal energy consumption [1]. The conventional controllers used in air conditioning systems are On/Off switch type, which, in addition to being non-optimal, do not provide optimal environmental conditions [2]. Modern air conditioning systems can manage the power consumption more efficiently[3]. In addition, the proportional-integral-derivative (PID) controllers are Preferred in air conditioning systems because of their simplicity, structure, ease of use, good stability, high reliability and zero steady-state error. Yet, the process of setting up an air conditioning system may take up to a few days to find the appropriate PID mode for the controller. This condition becomes much more difficult when there is a need for re-rendering, especially when the air conditioning system is large [4].

Many control loops are not properly set up in effect due to the lack of adequate knowledge of the control engineers of the process. This non-optimal setting increases energy consumption and, at the same time, leads to improper performance of the system under different conditions, and thus, in addition to being nonoptimal, it does not provide optimal environmental conditions [5]. This is very important when it is necessary to maintain an environment in particular conditions (such as museums and sterilized rooms). On the other hand, due to the complexity and uncertainty in the variables, which is one of the main characteristics of the dynamic behavior of these systems, the use of more advanced controllers in this field is expanding. Therefore, the developing a mountable technology on air conditioning systems is very important [6-10].

Various controllers have been proposed in this regard. Some of these controllers are used to adjust the available PID controllers. In this case, depending on various conditions, the function of PID controller's gain factor is determined by the fuzzy logic. In some others, given the above-mentioned properties for air conditioning systems, several multi-input multi-output systems have been controlled using a central fuzzy controller [11]. 
On the other hand, multilevel neural networks are widely used today to estimate nonlinear relation between input and output variables with specific precision. Application of these networks in estimating the thermal load of air conditioning systems has yielded good results [12]. Estimation of thermal comfort as the main objective of air conditioning systems is estimated by different indices, the most important of which is the PMV (Predicted Mean Vote) coefficient, which is obtained from Fanger's comfort equation with repetitive solution.

In this study, a fuzzy controller was utilized to provide thermal comfort in an air conditioning system. In order to avoid the repetition of Fanger's equation, neural network was used to estimate thermal comfort. Using the neural network in the loopback path of the controller, PMV coefficient was used to create control commands. Results indicated good fuzzy controller response given the nonlinear properties of air conditioning systems. In addition, the neural network makes use of the thermal comfort feedback in real-time control.

\section{PROPOSED SYSTEM}

\subsection{System model}

Figure 1 shows the single-zone air conditioning system considered in this study. This system model consists of different parts, including heat exchanger, return air compressor, heating chamber, chiller for cold water supply in heat exchanger, connecting ducts, and damper, fresh and return air mixers. In the present study, it was assumed that the system works in cooling mode. Main system processes in cooling mode are:

a) First, $25 \%$ fresh air enters the system in flow combiner and is mixed with $75 \%$ return air (Mode 5).

b) Then, the mixed air in the flow combiner enters the heat exchanger to provide air conditioning and heat transfer (Mode 1). Here, through the filter the mixed air passes and then the chilled water-cooling coil.

c) Then, the air entering the heating chamber is removed from the heat exchanger (Mode 2).

d) The outside air enters the heating chamber to compensate for the apparent (actual) heat and the latent (moisture) heat load according to the system conditions.

e) At the end, the air of the heating chamber is pulled out by the compressor (Mode 4), and $75 \%$ of it is returned to the system and the rest exits the system.

In this system, the airflow rate is set by the compressor speed. As the compressor speed increases, air discharge also increases. In addition, cold water discharge is regulated by a variable speed pump.

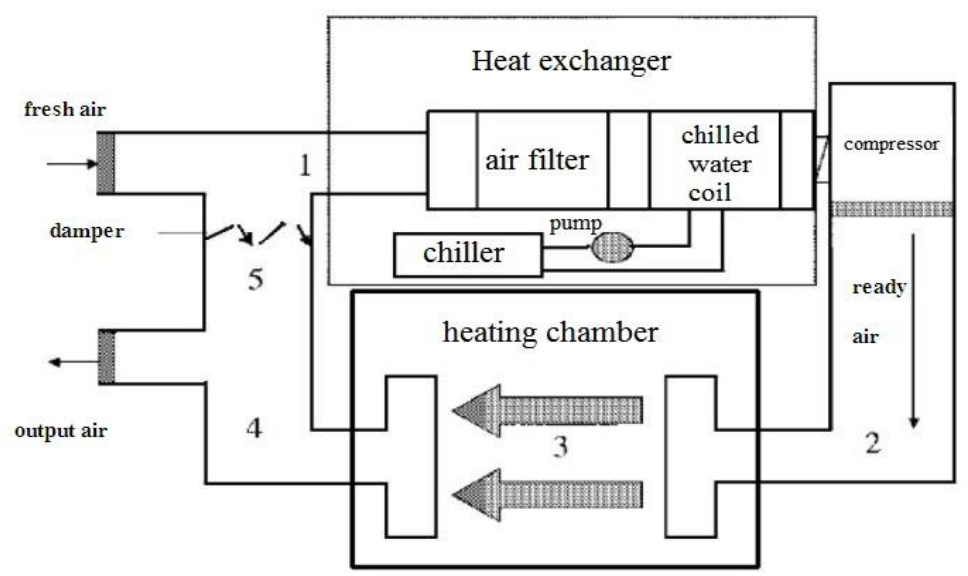

Figure 1. Single-zone air conditioning system

As seen in the Figure 1, air conditioning systems have many parts and components that make their modeling difficult, and almost impossible to achieve a definite model. Therefore, in most models presented for approximation of the system, some simplistic assumptions are used or identified by conventional methods, or the system model is obtained to control it using common identification methods. The differential equations of the dynamic behavior of the system shown in Figure 1 can be obtained from the expansion of energy equations and mass stability [13]:

$$
\dot{T}_{3}=\frac{f_{a}}{V_{s}}\left(T_{2}-T_{3}\right)-\frac{h_{f g} f_{a}}{C_{p a} V_{s}}\left(w_{s}-w_{3}\right)+\frac{1}{\rho_{a} C_{p a} V_{s}}\left(Q_{0}-h_{f g} M_{0}\right)
$$




$$
\begin{aligned}
& \dot{w}_{3}=\frac{f_{a}}{V_{s}}\left(w_{s}-w_{3}\right)-\frac{M_{0}}{\rho_{a} V_{s}} \\
& \dot{T}_{2}=\frac{f_{a}}{V_{h e}}\left(T_{3}-T_{2}\right)-\frac{0.25 f_{a}}{V_{h e}}\left(T_{0}-T_{3}\right)-\frac{h_{w} f_{a}}{C_{p a} V_{h e}}\left(0.25 w_{0}+0.75 w_{3}\right)-\left[\frac{\rho_{w} C_{p w} \Delta T_{h e}}{\rho_{a} C_{p a} V_{h e}}\right] f_{w}
\end{aligned}
$$

The variables associated with the system of the above equations are shown in Table 1.

Table 1. System variables

\begin{tabular}{lc}
\hline Outside air temperature & $T_{0}$ \\
Ready air temperature & $T_{2}$ \\
Heating chamber temperature & $T_{3}$ \\
Moisture load & $M_{0}$ \\
Sensible thermal load & $Q_{0}$ \\
Air mass density & $\rho_{a}$ \\
Water mass density & $\rho_{w}$ \\
Volumetric air flow & $f_{a}$ \\
Cold water flow & $f_{w}$ \\
Temperature change of heat exchanger & $\Delta T_{h e}$ \\
Liquid water enthalpy & $h_{w}$ \\
Water vapor enthalpy & $h_{f g}$ \\
Outside air relative humidity & $w_{0}$ \\
Ready air relative humidity & $w_{s}$ \\
Heating chamber relative humidity & $w_{3}$ \\
Heat exchanger volume & $V_{h e}$ \\
Heating chamber volume & $V_{s}$ \\
Specific air heat & $C_{p a}$ \\
Specific water heat & $C_{p w}$ \\
\hline
\end{tabular}

The conditions for writing the equations in air conditioning mode are as follows:

a) $25 \%$ fresh air is mixed with $75 \%$ return air from the heating chamber.

b) The whole mixed air passes through heat exchanger.

c) The air is introduced into the cycle through the fan and passes through the heat exchanger, leaving the rest out of it.

In addition, some of the assumptions considered in the above equations are:

a) Gases are assumed to be ideal and completely mixed.

b) The pressure is constant during the process.

c) Thermal loss and storage of components are ignored.

d) In order to control the system, the above dynamic equations can be represented by the following hypotheses in the space of state variables:

$$
\begin{array}{ll}
u_{1}=f_{a} & , u_{2}=f_{w} \\
x_{1}=T_{3} & , x_{2}=w_{3} \\
y_{1}=T_{3} & , y_{2}=w_{3}
\end{array}
$$

Equation coefficients are defined as:

$$
\begin{aligned}
& \alpha_{1}=\frac{1}{V_{s}}, \quad \alpha_{2}=\frac{h_{f g}}{C_{p a} V_{s}}, \quad \alpha_{3}=\frac{1}{\rho_{a} C_{p a} V_{s}}, \quad \alpha_{4}=\frac{1}{\rho_{a} V_{s}} \\
& \beta_{1}=\frac{1}{V_{h e}}, \quad \beta_{2}=\frac{\rho_{w} C_{p w} \Delta T_{h e}}{\rho_{a} C_{p a} V_{h e}}, \quad \beta_{3}=\frac{h_{w}}{C_{p a} V_{h e}}
\end{aligned}
$$

With these assumptions, we can show the above dynamic equation in the form of state variables as equations in (4).

$$
\begin{aligned}
& \dot{x}_{1}=a_{1} u_{1}\left(x_{3}-x_{1}\right)-a_{2} u_{1}\left(w_{s}-x_{2}\right)+a_{3}\left(Q_{0}-h_{f g} M_{0}\right) \\
& \dot{x}_{2}=a_{1} u_{1}\left(w_{s}-x_{2}\right)+a_{4} M_{0} \\
& \dot{x}_{3}=\beta_{1} u_{1}\left(x_{1}-x_{3}\right)+0.25 \beta_{1} u_{1}\left(T_{0}-x_{1}\right)-\beta_{3} u_{1}\left\{\left(0.25 w_{0}+0.75 x_{2}\right)-w_{s}\right\}-\beta_{2} u_{2}
\end{aligned}
$$




\subsection{Structure of fuzzy controller with thermal comfort feedback}

The general construction of the proposed control system is illustrated in Figure 2. In this system, a 2-input 2-output fuzzy controller is used. The input variables of the controller are thermal comfort coefficient with its rate of change. The control variables of the air conditioning system are airflow and refrigerant flow $\left(f_{w}\right.$ and $f_{a}$ ), which are respectively regulated valves and variable speed compressors. The range of variations of input and control variables are illustrated in Table 2.

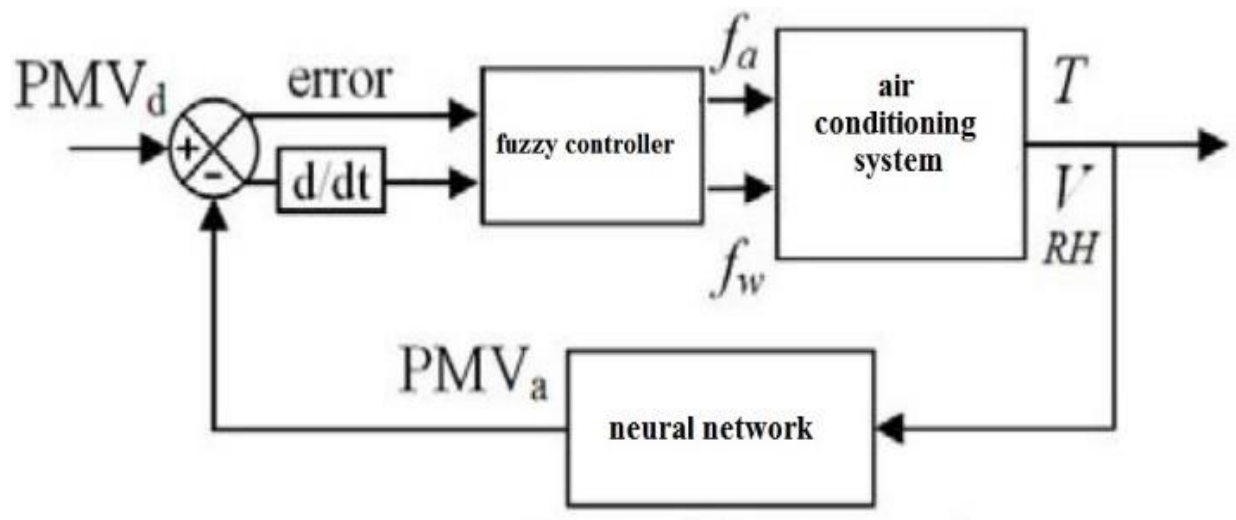

Thermal comfort index calculation

Figure 2. Control system diagram with comfort feedback

Table 2. Range of changes in controller variables

\begin{tabular}{ccc}
\hline & Min & Max \\
\hline PMV error & -3.5 & 3.5 \\
PMV & -1.5 & 1.5 \\
error_dot & 1 & 3.5 \\
$\mathrm{f}_{\mathrm{a}}$ & 1.5 & 1.5 \\
$\mathrm{f}_{\mathrm{w}}$ & 0.5 \\
\hline
\end{tabular}

\subsection{Thermal comfort coefficient}

Physiologically, thermal comfort conditions are a range of temperature and humidity in which the mechanism of body temperature regulation is minimized. The determination of the comfort zone of the installation systems affects not only the size of the heating and cooling devices, but also the thickness of the insulation and the energy consumption in the heating chamber. The most common method for estimating thermal comfort is to use the thermal comfort coefficient (PMA) provided by Fanger [14, 15].

PMV is a function of two human variables and four environmental variables [16]. These variables include type of clothing, human activity, temperature, air relative humidity, air velocity, and mean radiation temperature. PMV values lie between -3 and +3 , which change proportional to the feeling of occupants from cold to hot [17], and the baseline shows good conditions in terms of thermal comfort as shown in Figure 3.

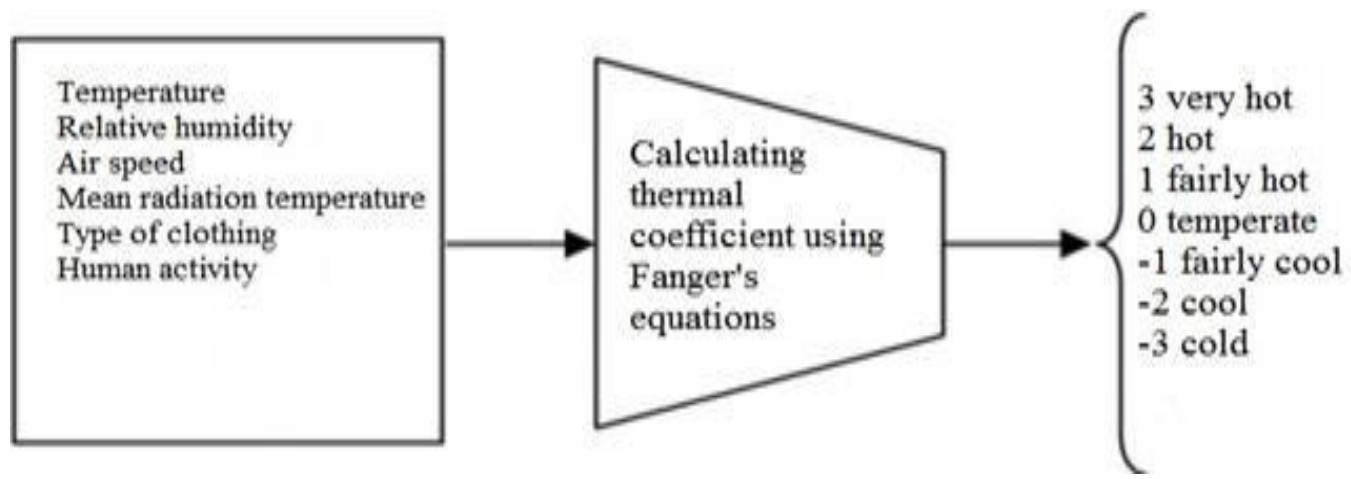

Figure 3. Thermal comfort coefficient

Thermal comfort control via air conditioning system using fuzzy neural network... (Somaye A. Mohamadi) 
Thermal comfort coefficient is obtained using the following relation:

$$
\begin{aligned}
& P M V=\left(0.325 e^{-0.042 M}+0.032\right)\left[M-0.35\left(43-0.061 M-P_{v}\right)-0.42(M-50)-0.0023 M\left(44-P_{v}\right)-\right. \\
& \left.0.0014 M\left(34-T_{i}\right)-3.4 \times 10^{-8} f_{c l}\left(\left(T_{c l}+273\right)^{4}-\left(T_{m r t}+273\right)^{4}\right)-f_{c l} h_{c}\left(T_{c l}-T_{i}\right)\right]
\end{aligned}
$$

And,

$$
T_{c l}=35.7-0.032 M-0.18 I_{c l}\left[3.4 \times 10^{-8} f_{c l}\left(\left(T_{c l}+273\right)^{4}-\left(T_{m r t}+273\right)^{4}\right)-f_{c l} h_{c}\left(T_{c l}+T_{i}\right)\right]
$$

Where, $T_{i}$ is the heating chamber temperature $\left({ }^{\circ} \mathrm{C}\right), \mathrm{T}_{\mathrm{mrt}}$ is mean radiation temperature, $M$ is human activity $\left(\mathrm{kcal} / \mathrm{h} \mathrm{m}^{2}\right), v$ is air velocity $(\mathrm{m} / \mathrm{s}), \mathrm{P}_{\mathrm{v}}$ is air vapor pressure $(\mathrm{mmHg}), \mathrm{I}_{\mathrm{cl}}$ is thermal resistance of clothing $(1 \mathrm{clo}=0.180 \mathrm{C} \mathrm{m} 2 \mathrm{~h} / \mathrm{cal}), \mathrm{h}_{\mathrm{c}}$ is heat transfer coefficient $\left(\mathrm{kcal} / \mathrm{m} 2 \mathrm{~h}{ }^{\circ} \mathrm{C}\right), f_{c l}$ is covered to uncovered body ratio, $T_{c l}$ is the temperature of clothes $\left({ }^{\circ} \mathrm{C}\right), \mathrm{RH}$ is relative humidity, and $P_{s}$ is the saturation vapor pressure.

As seen in $T_{c l}$, the formula proposed by Fanger involves the use of repetitive numerical methods that are time consuming and impair its function to be used in real-time control systems. Therefore, using an explicit relationship between input variables and comfort coefficient makes it possible to use this coefficient as the control system feedback. Recently, neural networks have been successfully used to identify and estimate the heat load and control air conditioning systems. According to the properties mentioned in [18-20], the use of multilevel neural network for calculating the comfort coefficient is proposed instead of the Fanger's comfort equation. In the neural network used in this study, temperature, relative humidity and air velocity in the heat exchanger are considered as network input and human variables and mean temperature of radiation are considered constant. The temperature and relative humidity are obtained directly from the dynamic equations and air velocity is considered as a linear function of the volumetric flow of air. The output of the neural network is the comfort coefficient, which is used as a feedback signal.

\subsection{Use of neural network in calculation of thermal comfort coefficient}

Multi-layer neural networks have been widely used to estimate the nonlinear relationship between input and output variables with a certain level of accuracy [21-23]. Recently, neural networks have been successfully used to identify and estimate the heat load and control air conditioning systems [24-27]. In view of the properties mentioned in [18], the use of multilevel neural network is proposed to calculate the thermal comfort coefficient instead of Fanger's equation. The proposed neural network consists of four layers of $6 \times 8 \times 4 \times 1$, where the total squared error of the network in comfort coefficient estimation was 0.11 . The input of this network is the same as the inputs to the Fanger's equations. In this way, the comfort coefficient could be calculated simultaneously using this neural network and used on the loopback path of the fuzzy controller. In the neural network used in this study, temperature, relative humidity and air velocity in the heat exchanger are considered as inputs and human variables and mean temperature of radiation are considered constant. Temperature and relative humidity were obtained directly from the dynamic equations and the air velocity was considered as a linear function of the volumetric flow of the input air. The output of the neural network is the comfort coefficient, which is used as a feedback signal.

\subsection{Adjusting the controller parameters}

The controller's parameters are adjusted according to the thermal comfort feedback signal and the rate of its change. Fuzzy controller rules for volumetric airflows $\left(f_{c}\right)$ and refrigerant flow $\left(f_{w}\right)$ are shown in Tables 3 and 4 .

Table 3. Fuzzy rules for $f_{a}$

\begin{tabular}{cccc} 
& & & \\
PMV error_dot & & & \\
\hline NB & PB & PB & ZE \\
ZE & PB & ZE & NB \\
PB & PB & NB & NB \\
\hline
\end{tabular}

Table 4. Fuzzy rules for $\mathrm{f}_{\mathrm{a}}$

\begin{tabular}{cccc} 
PMV error & & & \\
\hline NB & & & \\
ZE & NB & NB & ZE \\
PB & NB & ZE & PB \\
& NB & PB & PB \\
\hline
\end{tabular}

Regarding the range of variations specified in Table 2, membership functions of the triangular variables are considered. In the combination of rules, the min-max deduction is used and the defuzzification of the surface center is used to defuzz the output variables. Fuzzy controller surfaces with thermal comfort feedback are shown in Figures 4 and 5 for each of the output variables. Note that the baseline for the comfort coefficient is zero. 


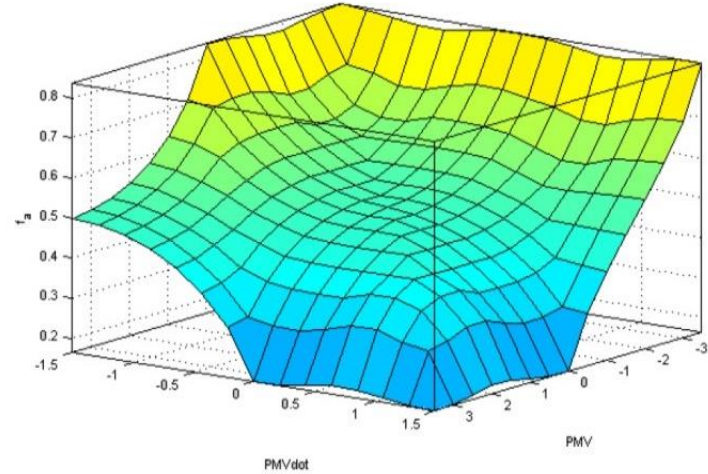

Figure 4. fa Control Surface

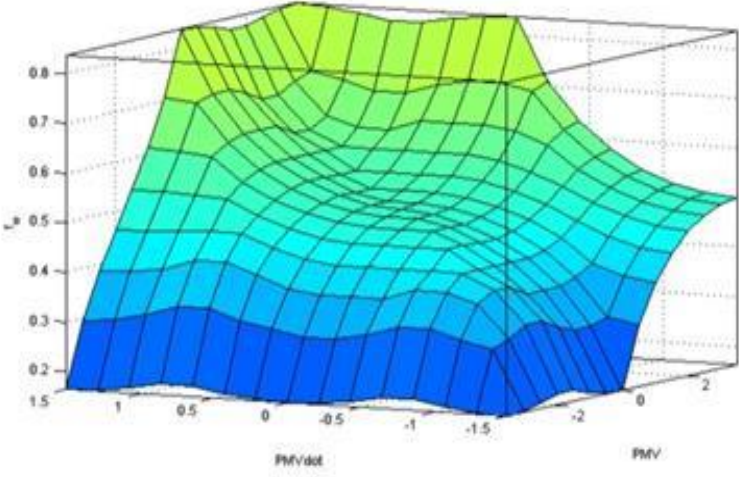

Figure 5. $f_{w}$ Control Surface

\section{SYSTEM FUNCTION SIMULATION IN MATLAB AND EXAMINING THE RESULTS}

To evaluate the function of the suggested controller, the proposed model was simulated in MATLAB/ SIMULINK. In addition, numerical values and reference system variables were used for simulation, which are related to the air conditioning system of the Central Bank of the Islamic Republic of Iran during a relatively long period of work. The control system response to the optimal thermal comfort input (PMV=0) is shown in Figure 6. As can be seen, the controller can provide optimum thermal comfort during a suitable period of time (300 seconds). Numerical Values and parameters of the system as shown in Table 5.

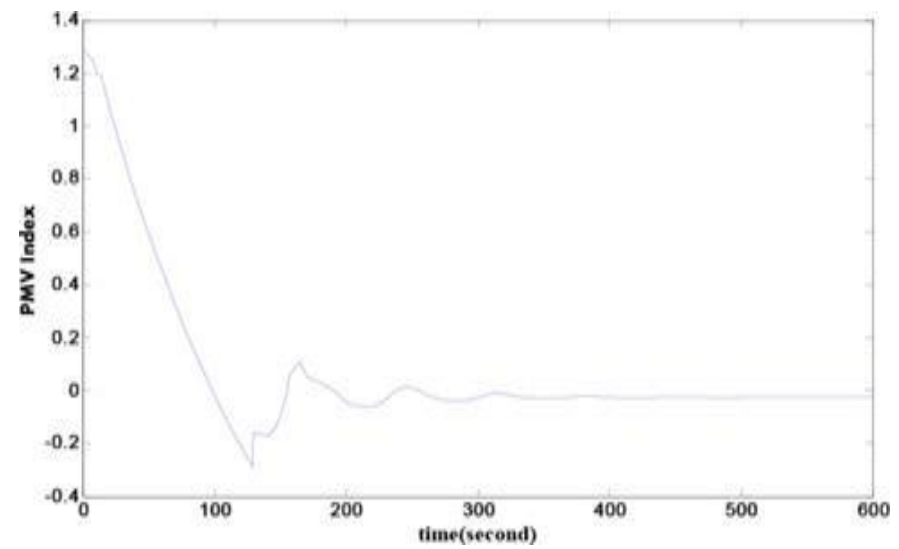

Figure 6. System response using fuzzy controller and neural network feedback
Table 5. Numerical values and parameters

\begin{tabular}{c} 
of the system \\
$T_{0}=30^{\circ} \mathrm{C}$ \\
$T_{2}=16.75^{\circ} \mathrm{C}$ \\
$T_{3}=24^{\circ} \mathrm{C}$ \\
$M_{0}=0.000117 \mathrm{~kg} / \mathrm{s}$ \\
$Q_{0}=22500 \mathrm{~J}$ \\
$\rho_{a}=1.1853 \mathrm{~kg} / \mathrm{m}^{3}$ \\
$\rho_{w}=1 \mathrm{~kg} / \mathrm{lit}$ \\
$\Delta T_{h e}=7{ }^{\circ} \mathrm{C}$ \\
$h_{w}=790840 \mathrm{~J} / \mathrm{kg}$ \\
$h_{f g}=2508009.5 \mathrm{~J} / \mathrm{kg}$ \\
$w_{0}=0.0081994 \mathrm{~kg} \mathrm{H} \mathrm{H}_{2} \mathrm{O} / \mathrm{kg} \mathrm{dry}$ \\
$w_{s}=0.0080 \mathrm{~kg} \mathrm{H} \mathrm{O} / \mathrm{kg} \mathrm{dry}$ \\
$w_{0}=0.0080380104 \mathrm{~kg} \mathrm{H} \mathrm{O} / \mathrm{kg} \mathrm{dry}$ \\
$V_{h e}=1 \mathrm{~m}^{3}$ \\
$V_{s}=379.5 \mathrm{~m}$ \\
$C_{p a}=1004.832 \mathrm{~J} / \mathrm{kg} .{ }^{\circ} \mathrm{C}$ \\
$C_{p w}=4198 \mathrm{~J} / \mathrm{kg} .^{\circ} \mathrm{C}$ \\
\hline
\end{tabular}

\section{CONCLUSION}

In this study, the modeling and controlling of single-zone air conditioning system were considered. After providing the dynamic equations of the system, a fuzzy controller with comfort coefficient feedback was proposed to control the intended system. Estimation of comfort coefficient using neural network with environmental and human variables as inputs was performed simultaneously. The estimated value was used as a fuzzy controller feedback signal by being compared with the nominal value. The results indicated the optimal performance of the controller in providing thermal comfort. They also indicated the ability to use the neural network in the feedback path of real-time control systems with thermal comfort feedback.

\section{REFERENCES}

[1] C. S. Canbay, et al., "Evaluating performance indices of a shopping centre and implementing HVAC control principles to minimize energy usage," Energy and Buildings, vol. 36, no. 6, pp. 587-598, 2004.

[2] J. W. Moon and S. K. Jung, "Development of a thermal control algorithm using artificial neural network models for improved thermal comfort and energy efficiency in accommodation buildings," Applied Thermal Engineering, vol. 103, pp. 1135-1144, 2016. 
[3] M. Collotta, et al., "A dynamic fuzzy controller to meet thermal comfort by using neural network forecasted parameters as the input," Energies, vol. 7, no. 8, pp. 4727-4756, 2014.

[4] A. K. Pal, "Development of Neuro-Fuzzy Controller for Applications to HVAC System, Inverted Pendulum and Other Processes," International Journal of Computational Cognition, vol. 6, no. 2, pp. 1-6, 2008.

[5] T. Chaudhuri, et al., "A feedforward neural network based indoor-climate control framework for thermal comfort and energy saving in buildings," Applied Energy, vol. 248, pp. 44-53, Aug 2019.

[6] A. K. Pal and R. K. Mudi, "Self-tuning fuzzy PI controller and its application to HVAC systems," International Journal of Computational Cognition, vol. 6, no. 1, pp. 25-30, 2008.

[7] M. Mongkolwongrojn and V. Sarawit, "Implementation of Fuzzy Logic Control for Air Conditioning Systems," ICCAS, 2005.

[8] A. N. Azlina, et al., "Intelligent home automated system," Indonesian Journal of Electrical Engineering and Computer Science, vol. 15, no. 2, pp. 733-742, 2019.

[9] H. J. Yoon, et al., "Prediction of thermal environment in a large space using artificial neural network," Energies, vol. 11, no. 2, pp. 418-432, 2018.

[10] N. I. Ramli, et al., "Investigating thermal comfort for the classroom environment using IoT," Indonesian Journal of Electrical Engineering and Computer Science, vol. 9, no. 1, pp. 157-163, 2018.

[11] R. S. Fargus and C. Chapman, "Commercial PI-neural controller for the control of building services plant," UKACC International Conference on Control, vol. 2, pp. 1688-1693, 1998.

[12] A. E. Ben-Nakhi and M. A. Mahmoud, "Cooling load prediction for buildings using general regression neural networks," Energy Conversion and Management, vol. 45, no. 13, pp. 2127-2141, 2004.

[13] B. Argüello-Serrano and M. Vélez-Reyes, "Nonlinear control of a heating, ventilating, and air conditioning system with thermal load estimation," IEEE Transactions on Control Systems Technology, vol. 7, no. 1, pp. 56-63, 1999.

[14] P. O. Fanger, "Thermal comfort. Analysis and applications in environmental engineering," Copenhagen, Danish Technical Press, 1970.

[15] A. A. Malik, et al., "Statistical analysis using taguchi method for wind turbine in ducting system," Indonesian Journal of Electrical Engineering and Computer Science, vol. 15, no. 1, pp. 26-33, 2019.

[16] Z. Deng and Q. Chen, "Artificial neural network models using thermal sensations and occupants' behavior for predicting thermal comfort," Energy and Buildings, vol. 174, pp. 587-602, 2018.

[17] G. Gao, et al., "Energy-Efficient Thermal Comfort Control in Smart Buildings via Deep Reinforcement Learning," arXiv: 1901.04693, pp. 1-11, 2019.

[18] S. Atthajariyakul and T. Leephakpreeda, "Neural computing thermal comfort index for HVAC systems," Energy Conversion and Management, vol. 46, no. 15-16, pp. 2553-2565, 2005.

[19] G. C. Cardarilli et al., "Approximated computing for low power neural networks," TELKOMNIKA Telecommunication Computing Electronics and Control., vol. 17, no. 3, pp. 1236-1241, 2019.

[20] B. D. Argo, et al., "A fuzzy micro-climate controller for small indoor aeroponics systems," TELKOMNIKA Telecommunication Computing Electronics and Control, vol. 17, no. 6, pp. 3019-3026, 2019.

[21] R. Escandón, et al., "Thermal comfort prediction in a building category: Artificial neural network generation from calibrated models for a social housing stock in southern Europe," Applied Thermal Engineering, vol. 150, pp. 492-505, 2019.

[22] N. A. Wahab, et al., "Artificial neural network based technique for energy management prediction," Indonesian Journal of Electrical Engineering and Computer Science, vol. 17, no. 1, pp. 94-101, 2019.

[23] R. F. Mustapa, et al., "Energy consumption prediction through linear and non-linear baseline energy model," Indonesian Journal of Electrical Engineering and Computer Science, vol. 17, no. 1, pp. 102-109, 2019.

[24] H. H. Bakr, et al., "A neuro-fuzzy sugeno-style HVAC control system for balancing thermal comfort and energy consumption," IJCCI 2017 - Proceedings of the 9th International Joint Conference on Computational Intelligence, pp. 419-426, 2017.

[25] P. M. Ferreira, et al., "Neural networks based predictive control for thermal comfort and energy savings in public buildings," Energy and Buildings, vol. 55, pp. 238-251, 2012.

[26] D. Palladino, et al., "Artificial Neural Networks For The Thermal Comfort Prediction In University Classrooms: An Innovative Application Of Pattern Recognition And Classification Neural Network, " 17th CIRIAF National Congress, 2017.

[27] X. K. Dang, et al., "Analyzing the sea weather effects to the ship maneuvering in Vietnam's sea from BinhThuan province to Ca Mau province based on fuzzy control method," TELKOMNIKA Telecommunication Computing Electronics and Control, vol. 16, no. 2, pp. 533-543, 2018. 